\title{
Dopamine Affects the Stability, Hydration, and Packing of Protofibrils and Fibrils of the Wild Type and Variants of $\alpha$-Synuclein ${ }^{\dagger}$
}

\author{
Cristian Follmer, ${ }^{\ddagger}$ Luciana Romão," Carla M. Einsiedler, ${ }^{\ddagger}$ Thaís C. R. Porto, ${ }^{\ddagger}$ Flávio Alves Lara, \\ Marlos Moncores, ${ }^{\perp}$ Gilberto Weissmüller, ${ }^{\perp}$ Hilal A. Lashuel, ${ }^{\#}$ Peter Lansbury, ${ }^{\dddot{~}}$ Vivaldo Moura Neto," \\ Jerson L. Silva, ${ }^{\ddagger}$ and Debora Foguel ${ }^{*, \sharp}$
}

Instituto de Bioquímica Médica, Programa de Biologia Estrutural, Universidade Federal do Rio de Janeiro, Rio de Janeiro 21941-590, Brazil, Departamento de Anatomia, Instituto de Ciências Biomédicas, Universidade Federal do Rio de Janeiro, Rio de Janeiro 21941-590, Brazil, Instituto de Biofísica Carlos Chagas Filho, Universidade Federal do Rio de Janeiro, Rio de Janeiro 21941-590, Brazil, Laboratory of Molecular Neurobiology and Neuroproteomics, Brain Mind Institute, Ecole Polytechnique Fédérale de Lausanne (EPFL), CH-1015 Lausanne, Switzerland, and Center for Neurological Diseases, Brigham and Women's Hospital and Department of Neurology, Harvard Medical School, Boston, Massachusetts 02115

Received September 8, 2006; Revised Manuscript Received November 4, 2006

\begin{abstract}
Parkinson's disease (PD) is characterized by the presence of cytoplasmic inclusions composed of $\alpha$-synuclein ( $\alpha$-syn) in dopaminergic neurons. This suggests a pivotal role of dopamine (DA) on PD development. Here, we show that DA modulates differently the stability of protofibrils (PF) and fibrils (F) composed of wild type or variants of $\alpha$-syn (A30P and A53T) as probed by high hydrostatic pressure (HHP). While in the absence of DA, all $\alpha$-syn PF exhibited identical stability, in its presence, the variantcomposed $\mathrm{PF}$ acquired a greater stability $\left(\mathrm{DAPF}_{\mathrm{wt}}<\mathrm{DAPF}_{\mathrm{A} 30 \mathrm{P}}=\mathrm{DAPF}_{\mathrm{A} 53 \mathrm{~T}}\right)$, implying that they would last longer, which could shed light onto why these mutations are so aggressive. When $\alpha$-syn was incubated for long times (18 days) in the presence of DA, we observed the formation of $\mathrm{F}$ by electronic microscopy, suggesting that the PF trapped in the presence of DA in short times can evolve into F. The stability of $F$ was also altered by DA. $\mathrm{DAF}_{\mathrm{wt}}$ was more labile than $\mathrm{F}_{\mathrm{wt}}$, indicating that the former would be more susceptible to breakage. $\mathrm{PF}_{\mathrm{A} 30 \mathrm{P}}$ and $\mathrm{DAPF}_{\mathrm{A} 30 \mathrm{P}}$, when added to mesencephalic and cortical neurons in culture, decreased the number and length of neurites and increased the number of apoptotic cells. Surprisingly, these toxic effects of $\mathrm{PF}_{\mathrm{A} 30 \mathrm{P}}$ and $\mathrm{DAPF}_{\mathrm{A} 30 \mathrm{P}}$ were practically abolished with HHP treatment, which was able to break the PF into smaller aggregates, as seen by atomic force microscopy. These results suggest that strategies aimed at breaking and/or clearing these aggregates is promising in alleviating the symptoms of PD.
\end{abstract}

Parkinson's disease $(\mathrm{PD})^{1}$ is the second most common neurodegenerative brain disorder, after Alzheimer's disease,

$\doteqdot$ This work was supported by grants from Conselho Nacional de Desenvolvimento Científico e Tecnológico (CNPq), Fundação Carlos Chagas Filho de Amparo à Pesquisa do Estado do Rio de Janeiro (FAPERJ), Millennium Institute for Structural Biology in Biomedicine and Biotechnology (CNPq Millennium Program), and Coordenação de Aperfeiçoamento de Pessoal de Nível Superior (CAPES) to D.F. and J.L.S.

* To whom correspondence should be addressed: Telephone: 5521-2562-6761. Fax: 55-21-3881-4155. E-mail: foguel@ bioqmed.ufrj.br.

† Instituto de Bioquímica Médica, Programa de Biologia Estrutural, Universidade Federal do Rio de Janeiro.

§ Present address: Departamento de Físico-Química, Instituto de Química, Universidade Federal do Rio de Janeiro, Rio de Janeiro 21949900, Brazil.

"Instituto de Ciências Biomédicas, Universidade Federal do Rio de Janeiro.

${ }^{\perp}$ Instituto de Biofísica Carlos Chagas Filho, Universidade Federal do Rio de Janeiro.

\# École Polytechnique Fédérale de Lausanne (EPFL).

"I Harvard Medical School.

${ }^{1}$ Abbreviations: PD, Parkinson's disease; $\alpha$-syn, $\alpha$-synuclein; HHP, high hydrostatic pressure; Tris, tris(hydroxymethyl-aminomethane); PF, protofibrils; F, fibrils; DAPF, dopamine-protofibrils; DAF, dopaminefibrils; AFM, atomic force microscopy; EM, eletronic microscopy; Thio$\mathrm{T}$, thioflavin-T; bis-ANS, 1,1'-bis(4-aniline-5-naphthalene sulfonate). affecting $\sim 1 \%$ of the population over 65 years of age (1). The symptoms of PD include difficulty in initiating movements, resting tremor, muscular rigidity, impaired postural reflexes, and bradykinesia, resulting from the loss of dopaminergic neurons and depletion of dopamine (DA) in the regions of the brain involved in motor functions [the substantia nigra $(\mathrm{SN})](2)$. The remaining neurons of the $\mathrm{SN}$ are characterized by the presence of an intracellular inclusion, known as Lewy bodies (LB), composed primarily of fibrillar $\alpha$-synuclein ( $\alpha$-syn) (3-6).

$\alpha$-syn is a 140 amino acid, "natively unfolded" protein with unknown function, although recent studies suggest that it may play a role in regulating the reserve pool of synaptic vesicles in the brain $(7,8)$. Genetic findings support a strong link between $\alpha$-syn and PD. Three mutations, A30P, E46K, and A53T, are linked to rare, early onset forms of PD (911). Duplication and triplication in the gene encoding $\alpha$-syn have also been described in familial PD (12), suggesting that increased expression is sufficient to cause PD. Although fewer than $10 \%$ of Parkinson's cases are linked to the presence of these mutations in the $\alpha$-syn gene (13), detailed characterization of these variants may provide critical insight 
into the mechanism by which these mutations alter the properties and/or function of $\alpha$-syn and thus may help to unravel the mechanism(s) of $\alpha$-syn-induced neurodegeneration in PD.

Neuropathologic findings based on postmortem examination of normal and diseased human brains as well as studies of transgenic mouse and flies overexpressing $\alpha$-syn (wild type and PD variants) support the hypothesis that prefibrillar $\alpha$-syn aggregates (PF) might be the pathogenic species in PD and suggest that fibril formation by $\alpha$-syn may be protective in PD $(14,15)$. First, a transgenic mouse model expressing human or mouse wild-type $\alpha$-syn shows PD-like symptoms, including degeneration of dopaminergic nerve terminals and formation of cytoplasmic, nonfibrillar $\alpha$-syn inclusions (16). Second, all mutations (A30P, A53T, and E46K) associated with familial PD accelerate $\alpha$-syn protofibril (A53T and A30P) and/or fibril (A53T and E46K) formation in vitro when compared to the wild-type protein $(11,17-$ 19). Furthermore, protofibrillar forms of $\alpha$-syn but not monomers or $\mathrm{F}$ were shown to permeabilize synthetic vesicles in vitro; the permeabilization activity of $\alpha$-syn was enhanced in the case of the disease variants A30P and A53T (20).

DA has been shown to interact with $\alpha$-syn to form $\alpha$-synDA adduct(s) which are thought to inhibit the conversion of $\alpha$-syn PF into F. These findings support the hypothesis that protofibrillar $\alpha$-syn is the pathogenic species and offer a possible explanation for the selective degeneration of dopaminergic neurons in PD $(15,21,22)$. The inhibitory activity of DA depends upon its oxidative breakdown and seems to be selective for the protofibril-fibril conversion $(15,21)$. In addition, DA, L-dopa, and other catecholamines were able to prevent and/or disaggregate amyloid $\mathrm{F}$ of $\alpha$-syn produced in vitro. These findings suggest that the $\alpha$-syn interaction with DA promotes the accumulation of potentially toxic protofibrillar intermediates both during amyloid formation and dissociation and support the hypothesis that $\alpha$-syn fibrillization reflects a detoxification strategy by which dopaminergic neurons sequester toxic intermediates.

Recently, we demonstrated that amyloid F composed of transthyretin or $\alpha$-syn were destabilized by high hydrostatic pressure (HHP) (23). In the case of $\alpha$-syn, the F produced from the disease-associated variants were more sensitive than wild-type $\mathrm{F}$ to HHP. This result suggests that, although all amyloid $\mathrm{F}$ share a common architecture (the cross $\beta$ sheet) $(24,25)$, regardless of the primary sequence or structure of the precursor amyloidogenic protein, the side-chain contacts play a significant role in the fine adjustment of fibril architecture, packing, and stability (23).

The aim of the present study was to evaluate the effects of DA on the stability of the in vitro grown $\mathrm{PF}$ and $\mathrm{F}$ composed of the wild type or variant (A53T and A30P) $\alpha$-syn. Any change in PF and F stabilities modulated by DA could represent an enhancement or a decrease in their longevity in dopaminergic neurons and consequently in their toxicity. Although other neuronal groups are also affected in PD, mainly in the patients bearing mutations (8), any change in the stability of these aggregates promoted by DA could shed light onto why the dopaminergic neurons are so vulnerable in PD. It has been shown that DA inhibits protofibril-fibril conversion $(15,21,26)$; however, in longer incubation times, as used here (18 days), we observe the appearance of $\mathrm{F}$ in the presence of DA. Thus, we grew PF and $F$ from wild-type and variant $\alpha$-syn in the absence or presence of DA (here called DAPF and DAF) and subjected all of them to HHP. Our results show that, in the absence of $\mathrm{DA}$, the conversion of PF into $\mathrm{F}$ is accompanied by a gain in stability, especially in the case of the wild type; this would render the nontoxic fibril a very stable species, freeing the nondopaminergic regions of the brain from the toxic effects of the PF. In the presence of DA (mimicking the conditions in dopaminergic neurons), the DAPF composed of the variants were more resistant to pressure denaturation than $\mathrm{DAPF}_{\mathrm{wt}}$, suggesting that the former would last longer in dopaminergic regions of the brain, thus explaining the faster progression of the disease in patients with $\alpha$-syn mutations with an increased susceptibility of the dopaminergic neurons in PD. We also investigated the toxicity of $\mathrm{PF}_{\mathrm{A} 30 \mathrm{P}}$ and $\mathrm{DAPF}_{\mathrm{A} 30 \mathrm{P}}$ added to cortical and mesencephalic embryonic neurons in culture. Both aggregates of A30P were highly toxic to these neurons. Interestingly, the HHP treatment significantly reduced the toxicity of $\mathrm{PF}_{\mathrm{A} 30 \mathrm{P}}$ and $\mathrm{DAPF}_{\mathrm{A} 30 \mathrm{P}}$, an observation that reinforces their toxic role in PD.

\section{EXPERIMENTAL PROCEDURES}

Production of $F$ and $P F$ of $\alpha$-syn. Recombinant $\alpha$-syn was expressed and purified as described (27). Solutions with 50 $\mu \mathrm{M}$ wild type, A30P, or A53T were incubated in buffer A [5 $\mathrm{mM}$ tris(hydroxymethyl-aminomethane) (Tris)- $\mathrm{HCl}$ and $100 \mathrm{mM} \mathrm{NaCl}$ at $\mathrm{pH} \mathrm{7.0]} \mathrm{at} 37{ }^{\circ} \mathrm{C}$ at atmospheric pressure under gentle stirring. Fibril formation was monitored by thioflavin $\mathrm{T}$ (Thio-T) binding until the steady state was reached. $\alpha$-syn PF were generated by incubating the protein solutions as described for 2 days only. Then, the solutions were centrifuged at $5000 \mathrm{~g}$ for $5 \mathrm{~min}$, and the supernatant was applied to the Superdex 200 (HR 10/30) column to remove the remaining monomers. The peak corresponding to the oligomeric form was collected and immediately subjected to HHP treatment. DAPF and DAF were produced as described $(21,22)$. Briefly, $50 \mu \mathrm{M}$ of the wild type or variants of $\alpha$-syn were incubated with equimolar concentrations of DA and aggregated for $2-3$ days at $37^{\circ} \mathrm{C}$ to produce DAPF or for 18 days to produce DAF. The influence of oxygen on DAF formation was investigated by incubating the samples under the same conditions but in an atmosphere enriched in nitrogen gas.

Thio-T Binding. Aliquots of $10 \mu \mathrm{L}$ of the aggregating solutions were withdrawn and mixed with $50 \mu \mathrm{L}$ of $500 \mu \mathrm{M}$ Thio-T solution (Sigma Co.) prepared in $50 \mathrm{mM}$ glycine at $\mathrm{pH} 8.5$, in a total volume of $1 \mathrm{~mL}$. Thio-T binding was evaluated by monitoring the changes in the emission spectra of Thio-T from 460 to $570 \mathrm{~nm}$ upon exciting the samples at $446 \mathrm{~nm}$. The presence of DA in the aggregating solutions did not interfere with the fluorescence emission of Thio-T or 1,1'-bis(4-aniline-5-naphthalene sulfonate) (bis-ANS).

Bis-ANS Binding. Aliquots of $5 \mu \mathrm{L}$ of the aggregating solutions were mixed with $5 \mu \mathrm{L}$ of an aqueous solution of $1.5 \mathrm{mM}$ bis-ANS (Molecular Probes) in a total volume of 1 $\mathrm{mL}$, and the binding of bis-ANS to the aggregates was determined by measuring the spectral area of the emission spectrum $(400-600 \mathrm{~nm})$ upon exciting the samples at 360 $\mathrm{nm}$.

Dissociation of $\alpha$-syn Aggregates by HHP. The aggregated protein samples were diluted to a final concentration of $\sim 16$ 
$\mu \mathrm{M}$ in buffer $\mathrm{A}$ and then subjected to HHP treatment. The high-pressure cell equipped with optical windows has already been described (28) and was purchased from ISS (Champaign, IL). To evaluate the average size distribution of $\alpha$-syn aggregates in solution, light scattering (LS) was measured by exciting the samples at $320 \mathrm{~nm}$ and collecting the light at $90^{\circ}$ from 315 to $325 \mathrm{~nm}$ in an ISS K2 spectrofluorometer. To evaluate the time dependence of the pressure-induced dissociation of $\alpha$-syn aggregates, kinetic experiments were performed by keeping the pressure fixed at 2170 bar and recording the LS at intervals of 5 min until the steady state was reached $(60 \mathrm{~min})$. In the experiments where the pressure dependence was measured, the pressure was increased from 1 to 3000 bar in steps of 270 bar, waiting 15-20 min before each measurement. All measurements were performed at 37 ${ }^{\circ} \mathrm{C}$ or as stated in the figure captions.

Transmission Electron Microscopy (TEM). The ultrastructure of the different aggregates of $\alpha$-syn was characterized using negative-staining TEM. The $\alpha$-syn F and $\alpha$-syn-DAF solutions $(50 \mu \mathrm{M})$ were diluted 12 -fold, and $10 \mu \mathrm{L}$ of this solution was deposited on a Formvar-coated copper grid. The samples were stained with $10 \mu \mathrm{L}$ of uranyl acetate $(2 \%$ aqueous solution) for $1 \mathrm{~min}$, dried, and then examined in a JEOL 1200EX, operated at $80 \mathrm{kV}$.

Atomic Force Microscopy (AFM). A total of $10 \mu \mathrm{L}$ of each sample was adsorbed onto the mica surface, dried at room temperature for $1-2 \mathrm{~h}$, and then rinsed twice gently with $50 \mu \mathrm{L}$ of MilliQ water before drying with nitrogen. AFM images were obtained at room temperature using a MFP-3D (Asylum Research, Santa Barbara, CA) in intermittent contact mode at $0.5 \mathrm{~Hz}$ and Si cantilevers (AC240TS, Olympus; with a spring constant of $1.32 \mathrm{~N} / \mathrm{m}$ and nominal tip radius lower than $10 \mathrm{~nm}$ ). Spring constants were measured by the thermal noise method. Image analysis was performed with the Igor Pro 5.0 image processing package (WaveMetrics, Inc., Portland, OR).

Neuron Primary Cultures. Neurons from the midbrain and cerebral cortex of 14-day-old Swiss mice (E14) were prepared as previously described (29) and modified by Garcia-Abreu and co-workers (30). All animals were kept under standard laboratory conditions according to National Institutes of Health guidelines. Mice anaesthetized by hypothermia were decapitated; the brain structures were removed; and the meninges were carefully stripped off. Dissociated cells were plated on coverslips previously coated with polyornithine $(1.5 \mu \mathrm{g} / \mathrm{mL}$, molecular weight $=41000$; Sigma Chem. Co., St Louis, MO), in serum-free neurobasal medium supplemented with B27 (Invitrogen, Carlsbad, CA). For immunocytochemistry assays, cells were plated on polyornithine-treated glass coverslips. The cultures were incubated at $37{ }^{\circ} \mathrm{C}$ in a humidified $5 \% \mathrm{CO}_{2}$ and $95 \%$ air chamber for $24 \mathrm{~h}$.

Immunocytochemistry. Immunocytochemistry was performed as previously described (31). Briefly, cultured cells were fixed with $4 \%$ paraformaldehyde for $20 \mathrm{~min}$ and permeabilized with $0.2 \%$ Triton $\mathrm{X}-100$ for $5 \mathrm{~min}$ at room temperature. After permeabilization, cells were blocked with $10 \%$ normal goat serum (Vector Laboratories, Inc., Burlingame, CA) in phosphate-buffered saline (PBS) (blocking solution) for $1 \mathrm{~h}$ and incubated overnight at room temperature with the specified primary antibodies diluted in blocking solution. For peroxidase staining, prior to the primary antibody incubation, endogenous peroxidase activity was abolished with $3 \% \mathrm{H}_{2} \mathrm{O}_{2}$ for $10 \mathrm{~min}$, followed by extensive washing with PBS. The primary antibody was mouse antihuman $\beta$-tubulin III antibody (Promega Corporation; 1:500). After primary antibody incubation, cells were extensively washed with PBS/10\% normal goat serum and incubated with secondary antibodies for $1 \mathrm{~h}$ at room temperature. Secondary antibodies were conjugated with horseradish peroxidase (goat antimouse; Sigma Chemical Co.; 1:100) or with fluorescein isothyocyanate (sheep antimouse; Sigma Chemical Co.; 1:400). Peroxidase activity was revealed with 3,3'-diaminobenzidine (DAB peroxidase substrate kit; Vector Laboratories, Inc.). Nuclear DNA was counterstained with $0.1 \mu \mathrm{g} / \mathrm{mL}$ 4,6-diamidino-2-phenylindole (DAPI; Sigma) for $5 \mathrm{~min}$ at room temperature, washed with PBS, and mounted in fluorescence medium. Negative controls were performed by omitting the primary antibody during staining. In all cases, no reactivity was observed when the primary antibody was absent.

Toxicity of $\alpha$-syn PF and DAPF Composed of A30P to Neuronal Cell Cultures. After $24 \mathrm{~h}$ of incubation, neuron cultures were treated with either $\mathrm{PF}_{\mathrm{A} 30 \mathrm{P}}$ or $\mathrm{DAPF}_{\mathrm{A} 30 \mathrm{P}}$ generated by incubation of $50 \mu \mathrm{M}$ A30P for 2 days at $37^{\circ} \mathrm{C}$ in the absence or presence of DA $(50 \mu \mathrm{M})$, respectively, as explained above. The toxic effects of these aggregates (at a concentration of $10 \mu \mathrm{M}$ ) before and after HHP treatment (60 min under $2.7 \mathrm{kbar}$ at $37{ }^{\circ} \mathrm{C}$ ) were evaluated after $24 \mathrm{~h}$ of incubation in neuronal cell cultures. Toxicity was evaluated by counting the number of neurites per neuron, their length, and also analyzing nuclear fragmentation. Neurons were maintained in serum-free medium supplemented with B27. Buffer A was used as a control.

Morphometry and Statistical Analysis. Neurons stained with $\beta$-tubulin III antibody were photographed using a Nikon microscope (Nikon Eclipse TE300). Photos were used to analyze the number of neurites and the total neurite length by using the Sigma Scan Pro Software (Jandel Scientific). In each experiment (at least three independent experiments were done), about 100 neurons per well, encompassing five randomly chosen fields, were scored per condition. The data were stored and analyzed graphically and statistically using the Sigma Scanplot and Microsoft Excel version 7.0.

\section{RESULTS}

PF Are Lesser Packed than F: Effects of DA on Protofibril Stability. To examine the effect of DA on the stability of $\alpha$-syn PF, we produced purified, 2-day-old PF in the absence (called PF) or presence (called DAPF) of DA using wildtype, A30P, or A53T proteins. Using electronic microscopy (EM) and AFM, we were able to confirm the absence of mature $\mathrm{F}$ in all of these preparations. By EM imaging (parts $\mathrm{A}$ and $\mathrm{B}$ of Figure 1), the $\mathrm{PF}_{\mathrm{A} 30 \mathrm{P}}$ and $\mathrm{DAPF}_{\mathrm{A} 30 \mathrm{P}}$ solutions presented small spherical aggregates with very few short $\mathrm{F}$. When these solutions were imaged by AFM (parts C and D of Figure 1, respectively), the spherical aggregates were shown to be heterogeneous in diameter (graphs below $\mathrm{C}$ and D). The diameter of the $\mathrm{PF}_{\mathrm{A} 30 \mathrm{P}}$ ranged in size from 90 to $240 \mathrm{~nm}$ (graph below C), while the diameter of the $\mathrm{DAPF}_{\mathrm{A} 30 \mathrm{P}}$, although more homogeneous, ranged from 180 to $240 \mathrm{~nm}$ (graph below D). The images of the PF and DAPF composed of the wild-type and A53T proteins were very similar and are not presented. 


\section{EM}

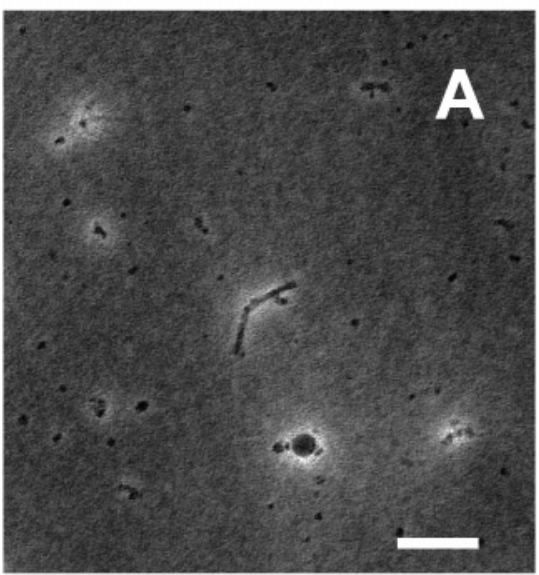

DA-PF

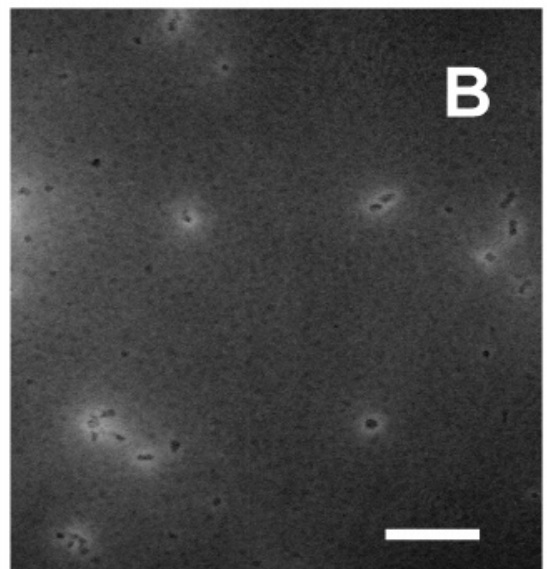

AFM

before HHP
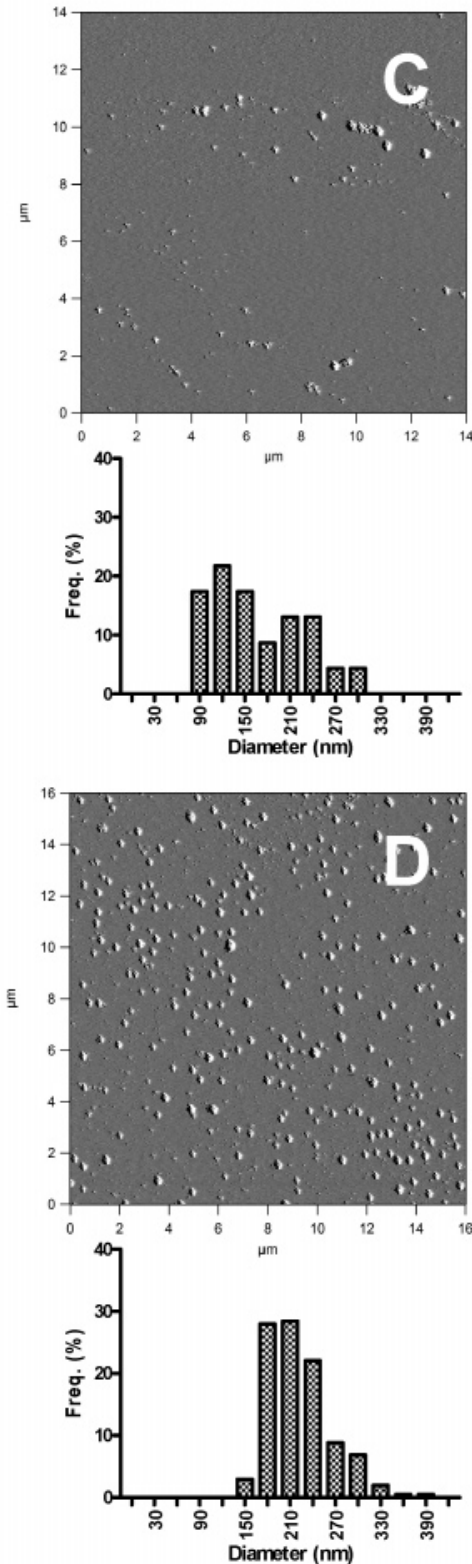

after HHP
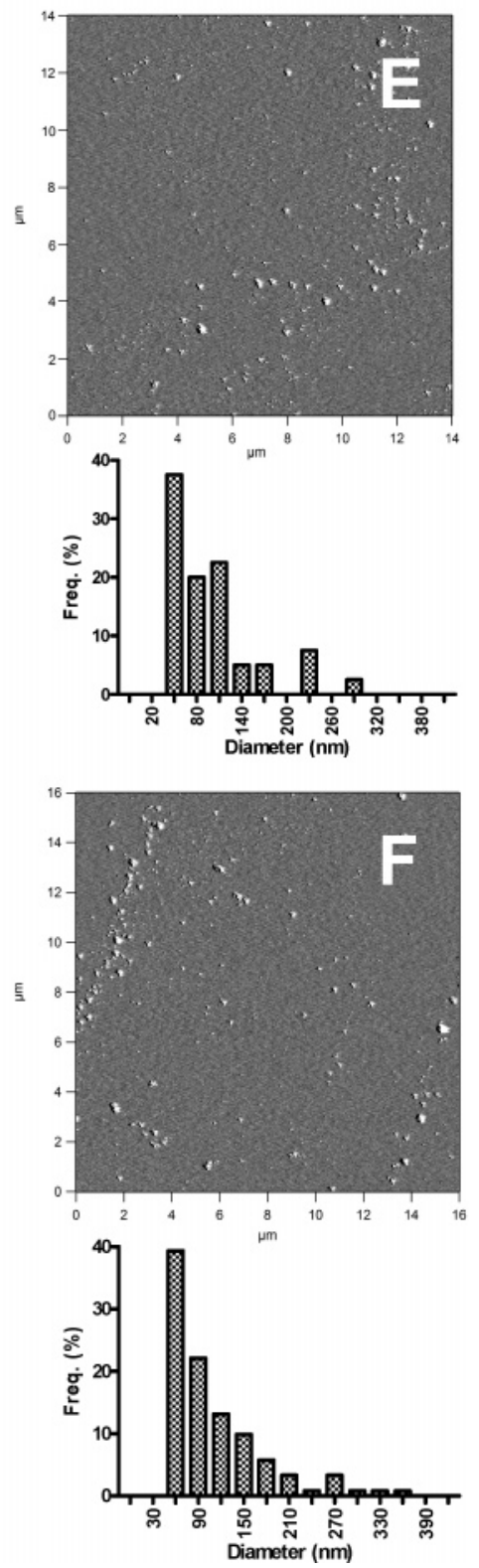

FIGURE 1: Analyzing the morphology of the $\mathrm{PF}_{\mathrm{A} 30 \mathrm{P}}$ and $\mathrm{DAPF}_{\mathrm{A} 30 \mathrm{P}}$ by EM and AFM. A30P $(50 \mu \mathrm{M})$ was incubated under aggregating conditions in the absence (PF) or presence of $50 \mu \mathrm{M}$ DA (DAPF) and imaged by $\mathrm{EM}(\mathrm{PF}=\mathrm{A}$, and $\mathrm{DAPF}=\mathrm{B})$ and $\mathrm{AFM}(\mathrm{PF}=\mathrm{C}$ and $\mathrm{E}$, and $\mathrm{DAPF}=\mathrm{D}$ and F). These samples were subjected to $2170 \mathrm{bar} / \mathrm{h}$ at $37^{\circ} \mathrm{C}$ and then analyzed by $\mathrm{AFM}(\mathrm{E}$ and $\mathrm{F})$. In $\mathrm{AFM}$ images, the diameters of the aggregates were measured and are shown in the graphs below each image. Scale: $\mathrm{EM}=150 \mathrm{~nm}$.

The morphology of the $\alpha$-syn PF has already been characterized by EM and AFM, where several different morphologies were described, including spherical, annular, pore-like, tube-like, and chain-like structures, and the extent of each species observed is hightly dependent upon the medium conditions (salts and $\mathrm{pH}$ ) as well as on the time of incubation (32). It has been shown that $\alpha$-syn forms spherical oligomers in the presence of DA (12 h of incubation at 37 ${ }^{\circ} \mathrm{C}$ ), displaying a diameter of about $25 \mathrm{~nm}$ based on AFM data (33). Here, we have used a longer incubation time (2 days), and this could explain the larger diameter observed for the PF.

When all of these PF and DAPF were on hand, their stabilities were then probed by subjecting them to increasing pressures while monitoring the changes the LS to infer about their integrity (Figure 2). Figure 2A shows that the LS signal decreased by $\sim 90 \%$ for all three PF samples, compatible with their dissociation into smaller species. Interestingly, in the absence of DA, all three PF exhibited virtually identical stability against HHP. The $p_{1 / 2}$ values (pressure required to achieve $50 \%$ dissociation) were in the range of 1000-1300 bar (Table 1). After pressure removal, the LS values remained low (isolated symbols on the left), suggesting the irreversibility of the process. This irreversible behavior is expected because aggregation of $\alpha$-syn depends upon sample agitation. In the case of the mature $\mathrm{F}$, as we reported before (23), there were marked differences in stability among wild type and variants, where $\mathrm{F}_{\mathrm{wt}}$ presented the highest stability followed by $\mathrm{F}_{\mathrm{A} 30 \mathrm{P}}$ and $\mathrm{F}_{\mathrm{A} 53 \mathrm{~T}}$ (Table 1 and see also hollow symbols in the right of Figure 4 ). When these data are taken together, 

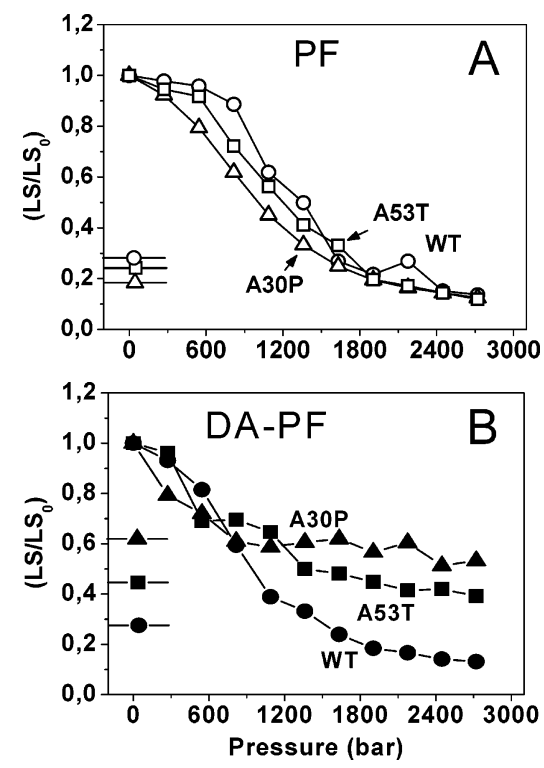

FIGURE 2: Pressure-induced dissociation of PF and DAPF composed of wild type or variants of $\alpha$-syn. A total of $50 \mu \mathrm{M}$ of each soluble $\alpha$-syn was incubated for 2 days under aggregating conditions in the absence (PF) or presence of $50 \mu \mathrm{M}$ DA (DAPF). Then, the solutions were centrifuged to remove large aggregates, and the supernatant was applied to the Superdex 200 (HR 10/30) column to remove the remaining monomers. The peak corresponding to the oligomerers was collected and immediately subjected to increasing pressures at $37^{\circ} \mathrm{C}$, and the LS was recorded and divided by the initial value $\left(\mathrm{LS} / \mathrm{LS}_{0}\right)$. A and $\mathrm{B}$ show, respectively, the pressure-dissociation profiles of the PF and DAPF. Wild type $(O$ and $\bullet$ ), A30P ( $\triangle$ and $\Delta$ ), and A53T ( $\square$ and $\mathbf{\square}$ ). The isolated symbols on the left represent the LS values observed after decompression. Data are means of at least three independent experiments.

Table 1: $p_{1 / 2}$ Values for the Dissociation of All Aggregates of $\alpha$-syn Calculated from Figures 2 and $3^{a}$

\begin{tabular}{lrrr}
\hline & wild type (bar) & A30P (bar) & A53T (bar) \\
\hline PF & $1350 \pm 210$ & $1000 \pm 90$ & $1200 \pm 120$ \\
F (23) & 2250 & 1650 & 950 \\
DAPF & $940 \pm 130$ & ND $^{b}$ & ND \\
DAF & $1100 \pm 110$ & ND & $1850 \pm 190$ \\
\hline
\end{tabular}

${ }^{a}$ Data are means \pm standard error of the mean of at least three independent experiments. ${ }^{b} \mathrm{ND}=$ values not accessible because of incomplete dissociation under those conditions.

they suggest that, at the protofibrillar stage, the contacts within these aggregates are still weak and are dominated by the main-chain contacts with little contribution from the side chains of the amino acids. However, during maturation, the conversion of $\mathrm{PF}$ into $\mathrm{F}$ seems to be accompanied by structural changes within the fibril involving mainly sidechain contacts, which contribute to fibril stability and individuality.

In the presence of DA (Figure 2B), DAPF of $\alpha$-syn (wild type and variants) responded differently to HHP, with $\mathrm{DAPF}_{\mathrm{wt}}$ being less stable than the DAPF composed of variants (Table 1). Indeed, the latter dissociates by only 40$50 \%$, even at the highest pressure attainable in our experimental setup (3000 bar). Again, after pressure removal, the LS values remained low (isolated symbols on the left of B), suggesting the irreversibility of the process. Thus, the interaction between $\alpha$-syn PF and DA confers a great stability to the PF composed of the disease-associated $\alpha$-syn (A30P and $\mathrm{A} 53 \mathrm{~T}$ ) with a modest change in $\mathrm{PF}_{\mathrm{wt}}$ stability (the $p_{1 / 2}$ for the dissociation of $\mathrm{PF}_{\mathrm{wt}}$ and $\mathrm{DAPF}_{\mathrm{wt}}$ was almost the same, $\sim 1000$ bar). In addition, the presence of DA seems to anticipate PF individuality. These observations have important physiological implications, given that in dopaminergic neurons the presence of $\mathrm{DA}$ would stabilize the toxic $\mathrm{PF}_{\mathrm{A} 30 \mathrm{P}}$ and $\mathrm{PF}_{\mathrm{A} 30 \mathrm{~T}}$ species, which could explain the early onset of the disease in the patients bearing these mutations.

Production of $F$ in the Presence of DA $(D A F)$ at Long Incubation Times: Effects of DA on Fibril Stability. Under appropriate conditions, $\alpha$-syn fibrillization takes $\sim 6-7$ days $(20,26)$. In this time range, previous studies demonstrated that DA inhibits $\alpha$-syn fibrillization, resulting in the accumulation of oligomers and $\operatorname{PF}(15,21,32,33)$. It was also shown that an oxidized form of DA is responsible for this activity $(22,33)$. Here, $\alpha$-syn (wild type and variants) were incubated in the presence of DA for an extended period of time (18 days), resulting in the formation of amyloid $\mathrm{F}$ with a typical morphology (upper images in Figure 3A), suggesting that the PF formed in the presence of DA can evolve into amyloid $\mathrm{F}$. These $\mathrm{F}$ are referred to here as DAF.

Initially, we compared the binding of bis-ANS and Thio-T to the wild-type, A53T, and A30P DAF with that displayed by the respective fibril (Figure 3B), whose binding was taken as $100 \%$. As seen, the DAF composed of wild type or variants displayed only $\sim 10 \%$ of the total Thio- $\mathrm{T}$ binding capacity (hollow bars) of the fibril, while the bis-ANS binding to DAF (filled bars) was $\sim 40 \%$ of that of the fibril, except for A30P. It is possible that Thio-T and bis-ANS compete with DA for the same binding sites within the amyloid fibril, which could explain their diminished binding to these $\mathrm{F}$. When the proteins were incubated in the presence of DA in an inert atmosphere, Thio-T binding increased to $\sim 40 \%$ (hollow bars with an upper $\mathrm{N}_{2}$ in B), consistent with previously reported data demonstrating that an autoxidation product(s) of DA is the active species in binding and inhibiting $\alpha$-syn fibrillization $(21,22)$.

To evaluate the effects of DA on fibril stability, we subjected all DAF to HHP at $37{ }^{\circ} \mathrm{C}$ and the dissociation of the $\mathrm{F}$ was monitored by LS (Figure 3C). As seen, $\mathrm{DAF}_{\mathrm{wt}}$ $(\bullet)$ was the most unstable species, followed by $\mathrm{DAF}_{\mathrm{A} 53 \mathrm{~T}}(\mathbf{\square})$, while $\mathrm{DAF}_{\mathrm{A} 30 \mathrm{P}}(\mathbf{\Lambda})$ was only partially dissociated under these conditions. The $p_{1 / 2}$ values for the dissociation of $\mathrm{DAF}_{\mathrm{wt}}$ and $\mathrm{DAF}_{\mathrm{A} 53 \mathrm{~T}}$ were $1110 \pm 110$ and $1850 \pm 190$ bar, respectively (Table 1). Interestingly, in the case of the F formed in the absence of DA (23) (Table 1), the sequence of stability was exactly the opposite, with the variant-composed $\mathrm{F}$ being the most unstable species $\left(\mathrm{F}_{\mathrm{A} 53 \mathrm{~T}}<\mathrm{F}_{\mathrm{A} 30 \mathrm{P}}<\mathrm{F}_{\mathrm{wt}}\right)$. These results suggest an important role of DA in modulating $\mathrm{F}$ as well as PF (Figure 2B) stability.

Because $\mathrm{DAF}_{\mathrm{A} 30 \mathrm{P}}$ was poorly dissociated by $\mathrm{HHP}$ at 37 ${ }^{\circ} \mathrm{C}$, a pressure -titration curve was performed at $1{ }^{\circ} \mathrm{C}(\triangle$ in Figure $3 \mathrm{C}$ ). However, even at this low temperature, the dissociation of $\mathrm{DAF}_{\mathrm{A} 30 \mathrm{P}}$ was still incomplete, which suggests that hydrophobic interactions are not the main contributing factor in DAF stability.

Time-course experiments performed with all DAF confirmed the difference in stability among DAF (Figure 3D). While the complete dissociation of $\mathrm{DAF}_{\mathrm{wt}}$ at 2170 bar required less than $20 \mathrm{~min}(\mathbf{)})$, the dissociation of $\mathrm{DAF}_{\mathrm{A} 53 \mathrm{~T}}$ occurred in $\sim 40 \mathrm{~min}(\mathbf{\square})$. Again, $\mathrm{DAF}_{\mathrm{A} 30 \mathrm{P}}$ did not dissociate completely at this pressure value, and the LS decreased only $50 \%$, even after 60 min under high pressure $(\mathbf{\Lambda})$. Thus, the 


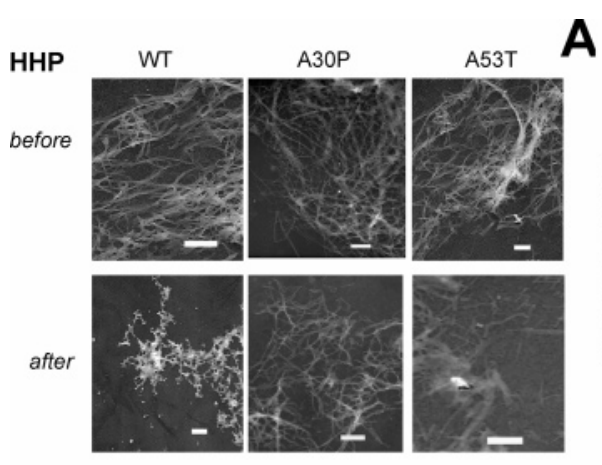

A
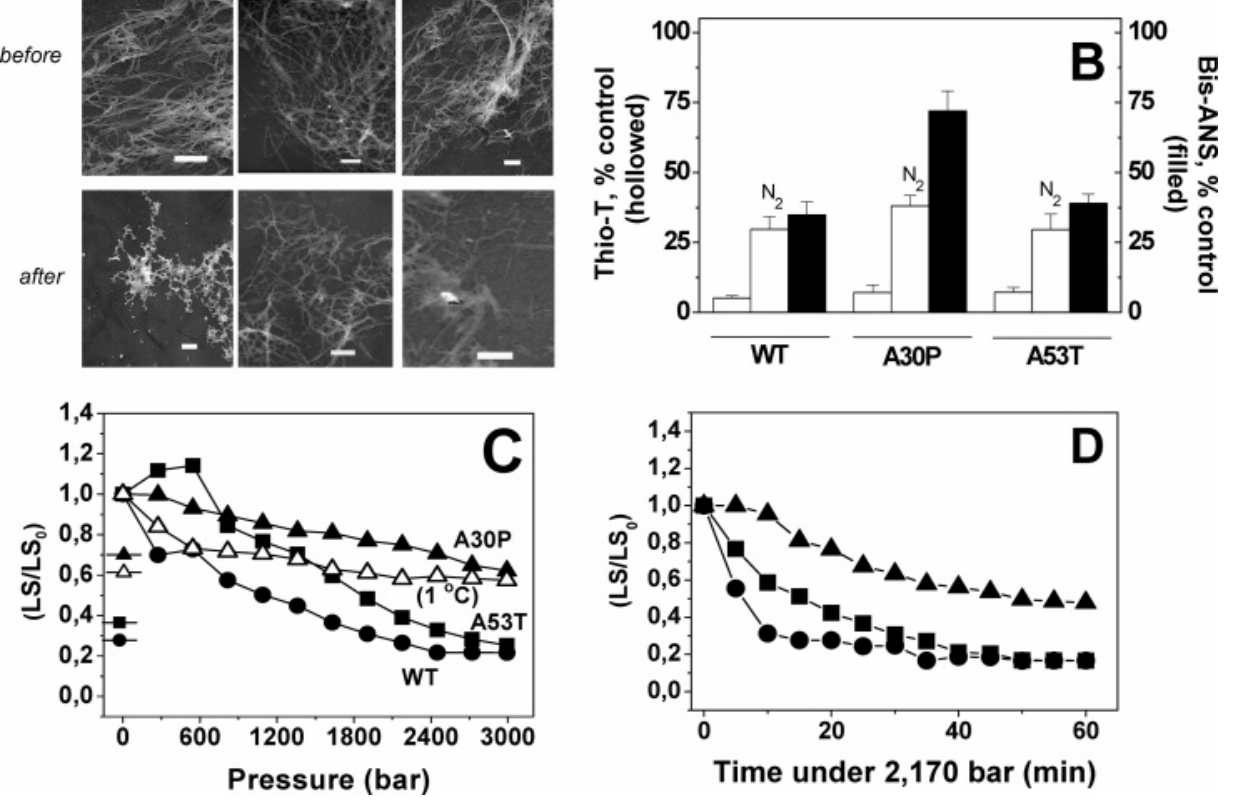

FIGURE 3: $\alpha$-syn forms $F$ in the presence of DA after long incubation times, comparing the effects of HHP on DAF composed of the wild type or variants. (A) EM images of the DAF formed after incubation of the wild type, A30P, and A53T (50 $\mu \mathrm{M})$ under agitation at $37{ }^{\circ} \mathrm{C}$ for 18 days in the presence of $50 \mu \mathrm{M}$ DA before (upper images) or after (2170 bar/h; lower images) HHP treatment (bar $=400 \mathrm{~nm})$. (B) Binding of Thio-T (hollow bars) and bis-ANS (filled bars) to DAF as compared to the control F, without DA (taken as 100\%). The influence of oxygen on the DA effect was evaluated by incubating the samples at $37^{\circ} \mathrm{C}$ in an atmosphere enriched in nitrogen gas (bars

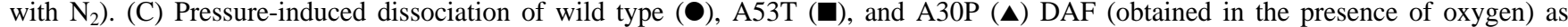
followed by the $\mathrm{LS}$ decrease at $37^{\circ} \mathrm{C}$. The pressure was increased in steps and recorded after 15 min at each pressure value. $(\triangle)$ Dissociation profile of $\mathrm{DAF}_{\mathrm{A} 30 \mathrm{P}}$ at $1{ }^{\circ} \mathrm{C}$. The isolated symbols on the left represent the LS values observed after decompression. (D) DAF were compressed at 2170 bar at $37^{\circ} \mathrm{C}$, and the time course of dissociation was evaluated by the decrease in the LS. Data are means of at least three independent experiments.

stability of DAF followed the same sequence as that of DAPF (wild type $<\mathrm{A} 53 \mathrm{~T}<\mathrm{A} 30 \mathrm{P}$ ) and was the opposite of that observed for the F grown in the absence of DA $(\mathrm{A} 53 \mathrm{~T}<$ A30P < wild type) (Table 1) (23).

This partial decrease in the LS observed with $\mathrm{DAF}_{\mathrm{A} 30 \mathrm{P}}$ might represent either the dissociation of a subpopulation of pressure-sensitive $\mathrm{DAF}_{\mathrm{A} 30 \mathrm{P}}$ or the homogeneous fragmentation of all $\mathrm{DAF}_{\mathrm{A} 30 \mathrm{P}}$ into oligomers still large in size. To answer this question, EM images of the species formed after decompression were obtained (lower images in Figure 3A). As seen, after decompression $(2170 \mathrm{bar} / \mathrm{h})$, while the $\mathrm{DAF}_{\mathrm{wt}}$ was drastically affected by the HHP treatment, in the $\mathrm{DAF}_{\mathrm{A} 30 \mathrm{P}}$, there was a large population of intact $\mathrm{F}$, suggesting that only a minor fraction of $\mathrm{DAF}_{\mathrm{A} 30 \mathrm{P}}$ may be sensitive to HHP. In the case of $\mathrm{DAF}_{\mathrm{A} 53 \mathrm{~T}}$, although several $\mathrm{F}$ were still present after pressure treatment, there was a considerable reduction in their concentration, because several fields of the EM grid presented little or no F to be imaged.

Differences in PF and F Stability Might Contribute to Dopaminergic Neuronal Loss in PD. In Figure 4, the dissociation profiles of all PF (left panels) and F (right panels) are grouped in pairs (grown in the absence (hollow symbols) or presence (filled symbols) of DA) to give an idea of what would be their expected behavior in nondopaminergic versus dopaminergic neurons. With the wild-type proteins (upper panels), the stabilities of the PF, DAPF, and DAF were almost identical $\left(p_{1 / 2} \sim 1000-1200\right.$ bar, Table 1 ), whereas the $\mathrm{F}_{\mathrm{wt}}$ was considerably more stable. This means that, in the dopaminergic region of the brain, the weak $\mathrm{DAF}_{\mathrm{wt}}$ would easily brake into smaller toxic species, while in the nondopaminergic regions, the nontoxic $\mathrm{F}_{\mathrm{wt}}\left(p_{1 / 2}=2250 \mathrm{bar}\right)$

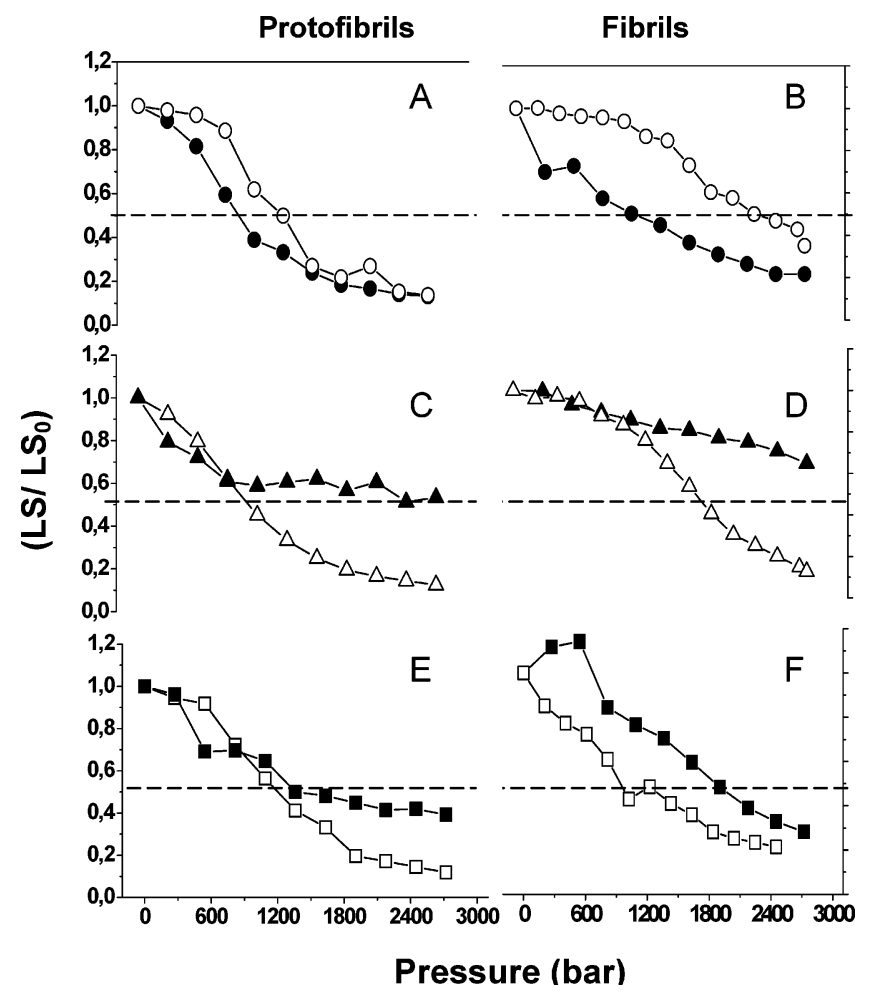

FIGURE 4: Comparing the stability of PF (left graphs) and F (right graph) grown in the absence $(O, \triangle$, and $\square)$ or presence $(\boldsymbol{O}, \mathbf{\Delta}$, and D) of DA. A and $\mathrm{B}=$ wild type, $\mathrm{C}$ and $\mathrm{D}=\mathrm{A} 30 \mathrm{P}$, and $\mathrm{E}$ and $\mathrm{F}$ $=\mathrm{A} 53 \mathrm{~T}$. Other conditions are the same as in Figures 2 and 3.

would prevail. This would tend to free the nondopaminergic regions of the brain from the toxic effects of the smaller 

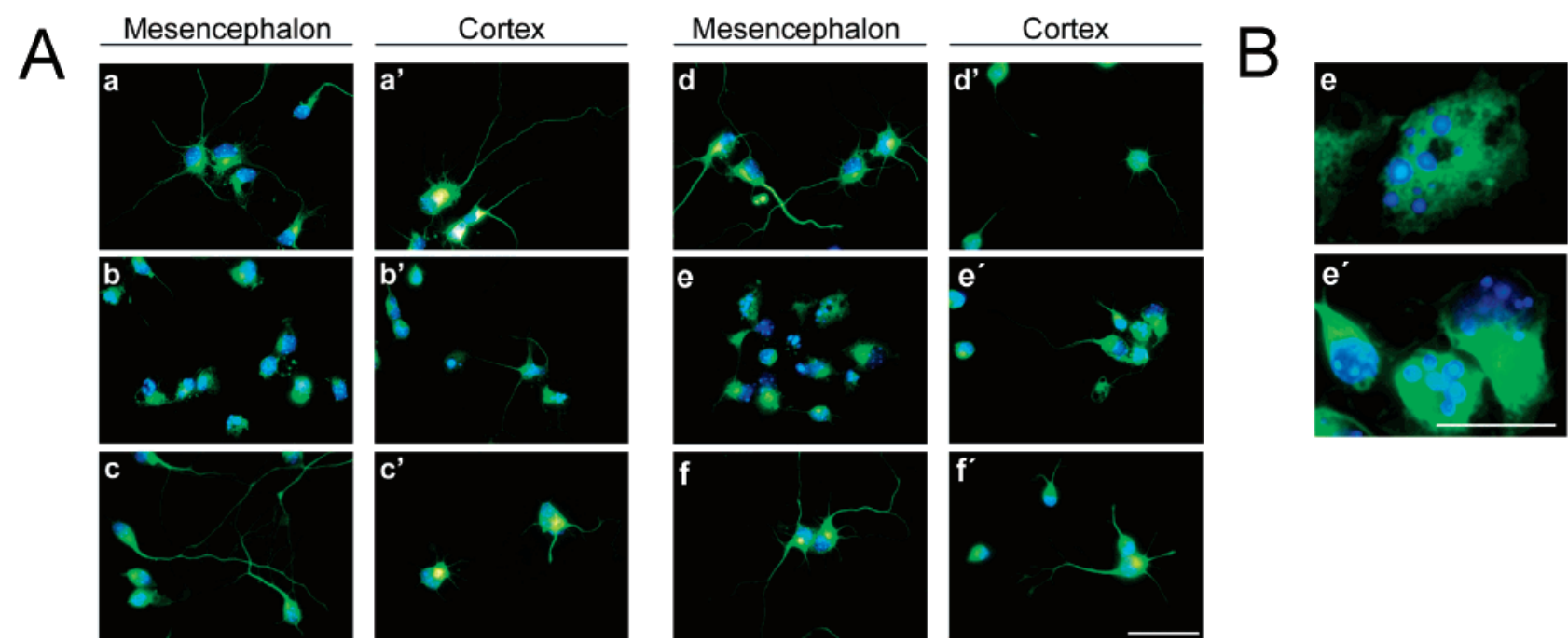

FIGURE 5: Evaluating the toxic effects of $\mathrm{PF}_{\mathrm{A} 30 \mathrm{P}}$ and $\mathrm{DAPF}_{\mathrm{A} 30 \mathrm{P}}$ to mesencephalic and cortical neurons in culture. (A) Images a-f are from the mesencephalic, and images $\mathrm{a}^{\prime}-\mathrm{f}^{\prime}$ are from the cortical neurons from a 14-day-old embryonic (E14) mouse brain maintained for $24 \mathrm{~h}$ in culture before subsequent treatment. Each cell culture was incubated for $24 \mathrm{~h}$ in the presence of a and a', buffer (5 mM Tris and $100 \mathrm{mM}$ $\mathrm{NaCl}$ at $\mathrm{pH} 7.0$ ); $\mathrm{b}$ and $\mathrm{b}^{\prime}, \mathrm{PF}_{\mathrm{A} 30 \mathrm{P}}$ (grown in the absence of $\mathrm{DA}$ for 2 days); c and $\mathrm{c}^{\prime}, \mathrm{PF}_{\mathrm{A} 30 \mathrm{P}}$ treated for 60 min at $2.7 \mathrm{kbar}$; $\mathrm{d}$ and d', 50 $\mu \mathrm{M}$ DA solution; e and $\mathrm{e}^{\prime}, \mathrm{DAPF}_{\mathrm{A} 30 \mathrm{P}}$ (grown for 2 days in the presence of $50 \mu \mathrm{M} \mathrm{DA}$ ); and f and $\mathrm{f}^{\prime}, \mathrm{DAPF}_{\mathrm{A} 30 \mathrm{P}}$ treated for 60 min at 2.7 kbar. Aggregate concentrations were $10 \mu \mathrm{M}$ (monomer concentration). The neurons were stained with $\beta$-tubulin III antibody (green) and DAPI (blue). (B) Magnification of the images shown in e (mesencephalic neurons treated with DAPF $\mathrm{A}_{\mathrm{A} 0 \mathrm{P}}$ ) and $\mathrm{e}^{\prime}$ (cortical neurons treated with $\left.\mathrm{DAPF}_{\mathrm{A} 30 \mathrm{P}}\right)$, where nuclear fragmentation as a sign of apoptosis is observed. Scale bar $=40 \mu \mathrm{m}\left(\mathrm{a}-\mathrm{f}^{\prime}\right)$ and $5 \mu \mathrm{m}($ lower images).

aggregates, and indeed, the sporadic form of the disease affects mostly the dopaminergic region (9).

In the case of the PF and $\mathrm{F}$ composed of the variants (parts $\mathrm{C}$ and $\mathrm{D}$ of Figure $4=\mathrm{A} 30 \mathrm{P}$, and parts $\mathrm{E}$ and $\mathrm{F}$ of Figure $4=$ A53T), DA alters considerably their stabilities. It is clear that DA enhances stability at the level of the variant PF (filled symbols on parts $\mathrm{A}, \mathrm{C}$, and $\mathrm{E}$ of Figure 4), which might mean that, in dopaminergic neurons, when the toxic PF are formed, they are already stable enough to persist and damage these neurons. This effect is not observed with the wildtype protein, where PF and DAPF have approximately equal stabilities (Figure 4A and Table 1). Thus, although the DAF composed of variants are more stable than their respective F (parts D and F of Figure 4), the effects of DA in terms of increasing stability are already perceptible at the level of PF. Thus, we can postulate from these data that DA renders the $\mathrm{PF}$ composed of the variants very stable, enabling them to evade the cellular strategies that might dissolve these toxic aggregates. This could explain their enhanced toxicity in the dopaminergic regions of the brain. In the nondopaminergic regions, $\mathrm{PF}$ composed of the variants are either very unstable (as in the case of A30P) or as stable as the F (as in the case of A53T).

The Toxicity of $P F_{A 30 P}$ and $D A P F_{A 30 P}$ to Neurons in Culture Is Eliminated by HHP Treatment. To further characterize the cytotoxic effect of the PF, DAPF, as well as the species recovered from the HHP treatment, we selected the A30P for this analysis. Initially, AFM imaging was employed to better characterize the morphology of the species present after HHP treatment (parts E and F of Figure 1 and graphs below them). As seen, after pressure treatment, the $\mathrm{PF}_{\mathrm{A} 30 \mathrm{P}}$ and $\mathrm{DAPF}_{\mathrm{A} 30 \mathrm{P}}$ solutions presented only spherical aggregates homogeneous in diameter (75-120 and 86-103 $\mathrm{nm}$, respectively), being smaller than the aggregates present before compression [diameter ranging from 130 to $182 \mathrm{~nm}$
(PF) and 213 to $224 \mathrm{~nm}$ (DAPF)]. Those values are 95\% of the confidence interval of the geometrical mean, and it suggests that HHP induces the fragmentation of these spherical aggregates into smaller species.

To evaluate the toxic effects of $\mathrm{PF}_{\mathrm{A} 30 \mathrm{P}}$ and $\mathrm{DAPF}_{\mathrm{A} 30 \mathrm{P}}$, these aggregates were added to mesencephalic and cortical neurons from 14-day-old embryonic (E14) mouse brains maintained for $24 \mathrm{~h}$ in culture before morphological analysis of the neurons. The length and number of neurites per neuron, as well as the morphology of the nuclei [DNA staining with 4,6-diamidino-2-phenylindole (DAPI)] were evaluated (Figures 5 and 6). These experiments were performed with $\mathrm{PF}$ (2-3 days old) because of the difficulty in keeping the solutions sterile for longer times, when $\mathrm{F}$ appear.

Figure 5A shows images of healthy mesencephalic (a) and cortical ( $\left.a^{\prime}\right)$ neurons in culture. They exhibited prolonged processes and no sign of nuclear fragmentation (not shown in detail). The addition of DA $(50 \mu \mathrm{M})$ to these neurons did not change their healthy appearance $\left(d-d^{\prime}\right)$. However, when $\mathrm{PF}_{\mathrm{A} 30 \mathrm{P}}\left(\mathrm{b}\right.$ and $\left.\mathrm{b}^{\prime}\right)$ or $\mathrm{DAPF}_{\mathrm{A} 30 \mathrm{P}}$ (e and $\mathrm{e}^{\prime}$ ) were present, neurite outgrowth and the number of neurites per neuron decreased dramatically, as further quantified in Figure 6. In addition, all of these toxic effects were accompanied by an evident nuclear fragmentation with an apparent preservation of the cytoplasm, suggesting an initial apoptotic process rather than necrosis induced by $\mathrm{PF}_{\mathrm{A} 30 \mathrm{P}}$ (not shown in magnification) and $\mathrm{DAPF}_{\mathrm{A} 30 \mathrm{P}}$ either in the mesencephalon (e in Figure 5B) or in the cortex ( $\mathrm{e}^{\prime}$ in Figure 5B).

Interestingly, the toxic effects of both $\mathrm{PF}_{\mathrm{A} 30 \mathrm{P}}$ and $\mathrm{DAPF}_{\mathrm{A} 30 \mathrm{P}}$ were strongly reduced when the samples were previously subjected to HHP treatment $(2700 \mathrm{bar} / \mathrm{h})\left(\mathrm{c}\right.$ and $\mathrm{c}^{\prime}$ and $\mathrm{f}$ and $\mathrm{f}^{\prime}$ in Figure 5A). As seen, these neurons presented prolonged processes and no sign of nuclear fragmentation (not shown in magnification). When these data are taken together, they suggest that, being able to break the PF and DAPF composed of A30P into smaller aggregates (parts D and F in Figure 

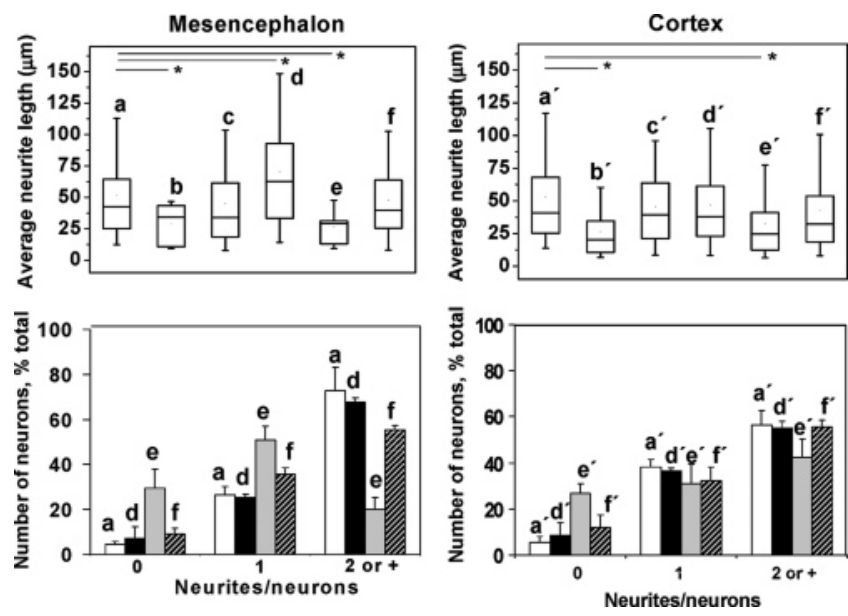

FIGURE 6: Evaluation of neuritogenesis in each cell culture treated with the aggregates of A30P shown in Figure 1. A total of 100 neurons chosen randomly were analyzed, and the results are expressed using the percentile plot, $(*) p<0.01$. Upper panels show the length of neurites from mesencephalic (left) and cortical (right) neurons growing in the conditions described in the Experimental Procedures. The boxes enclose the 25 th and 75 th percentiles and are bisected by the median; whiskers indicate the 5th and 95th percentiles. Note that the bars related to the pressure-treated samples ( $c$ and $f ; c^{\prime}$ and $f^{\prime}$ ) are similar to the controls (a and $a^{\prime}$ ). Also note that treatment with DA alone stimulated neurite growth in the mesencephalon (bar d). An asterisk represents significant differences $(p<0.01)$. Lower panels show the number of neurites per neuron $(0,1,2$, or more) in mesencephalon (left) or in the cortex (right). Again, the mesencephalic neurons treated with $\mathrm{DAPF}_{\mathrm{A} 30 \mathrm{P}}$ (bare) were more affected than the cortical neurons $\left(\mathrm{e}^{\prime}\right)$. The distribution of neurites per neuron in the cells incubated with pressure-treated $\mathrm{DAPF}_{\mathrm{A} 30 \mathrm{P}}\left(\mathrm{f}\right.$ and $\mathrm{f}^{\prime}$ ) was quite similar to the control.

Table 2: Average Neurite Length on Mesencephalic and Cortical Neurons from the Brains of E14 Mice Treated with Different Aggregates of A30P before and after HHP Treatment

\begin{tabular}{lcc}
\hline \multicolumn{1}{c}{ condition } & $\begin{array}{c}\text { mesencephalic } \\
\text { neurons }(\mu \mathbf{m})\end{array}$ & $\begin{array}{c}\text { cortical } \\
\text { neurons }(\mu \mathbf{m})\end{array}$ \\
\hline control (buffer) & $80-100$ & $90-100$ \\
$+\mathrm{PF}_{\mathrm{A} 30 \mathrm{P}}$ & 40 & 70 \\
+ after pressure $\mathrm{PF}_{\mathrm{A} 30 \mathrm{P}}$ & $80-100$ & $80-100$ \\
$+\mathrm{DA}(50 \mu \mathbf{M})$ & $130-140$ & $90-100$ \\
$+\mathrm{DAPF}_{\mathrm{A} 30 \mathrm{P}}$ & 40 & $70-80$ \\
+ after pressure $\mathrm{DAPF}_{\mathrm{A} 30 \mathrm{P}}$ & $80-100$ & $80-100$ \\
\hline
\end{tabular}

1), HHP treatment strongly reduces the associated toxicity of these aggregates to neurons in culture.

The number of neurites per neuron as well as neurite length were quantified as described in the Experimental Procedures and are presented in Figure 6 and Table 2. In mesencephalic cultures (left in Figure 6), the average neurite length of the neurons treated with PF (bar b) or DAPF (bar e) was much less $(40 \mu \mathrm{m})$ than the average length in the control cultures (80-100 $\mu \mathrm{m}$, bar a). The addition of DA to these neurons (bar d) increased neurite outgrowth $(130-140 \mu \mathrm{m}$ ), suggesting that they might be dopaminergic neurons.

In the case of the cortical neurons (right in Figure 6 and Table 2), the average neurite length was 90-100 $\mu \mathrm{m}$ (bar $\left.\mathrm{a}^{\prime}\right)$ and the presence of DA (bar d') did not change this value (90-100 $\mu \mathrm{m})$. As observed with the mesencephalic neurons, the presence of $\mathrm{PF}_{\mathrm{A} 30 \mathrm{P}}$ (bar b') or $\mathrm{DAPF}_{\mathrm{A} 30 \mathrm{P}}$ (bar e') decreased the average length of the neurites to 70 or $70-80 \mu \mathrm{m}$, respectively.

As mentioned before, the toxic effects of both $\mathrm{PF}_{\mathrm{A} 30 \mathrm{P}}$ and $\mathrm{DAPF}_{\mathrm{A} 30 \mathrm{P}}$ were greatly reduced when the samples were previously subjected to HHP treatment. As seen, the cultures incubated in the presence of the "after pressure PF" (bars c and $\mathrm{c}^{\prime}$ and Table 2) displayed the same neurite length (80$100 \mu \mathrm{m}$ in both neuron cultures) as the controls (bars a and $\mathrm{a}^{\prime}$ ), while the "after pressure DAPF" (bar $\mathrm{f}$ and $\mathrm{f}^{\prime}$ ) had the same neurite length as DA alone ( $d$ and d') $(80-100 \mu \mathrm{m}$ in both neuron cultures).

In regard to the number of neurons with 0,1 , or $\geq 2$ neurites (lower graphs in Figure 6), it is noteworthy that, in the control cultures, the majority of neurons have more than two neurites per neuron, whether in mesencephalon (bar a) or cortex (bar $\left.\mathrm{a}^{\prime}\right)$. DA alone did not affect the number of neurites/neuron either in the mesencephalon (bar d) or cortex (bar d'). The addition of DAPF to these cultures caused a significant reduction in the number of neurites/neuron (bars $\mathrm{e}$ and $\mathrm{e}^{\prime}$ ), where the majority of mesencephalic neurons present one neurite per neuron, while the majority of cortical neurons present one or more than two neurites. Interestingly, the pattern of neurite distribution was recovered in the cultures incubated in the presence of $\mathrm{DAPF}_{\mathrm{A} 30 \mathrm{P}}$ previously subjected to HHP treatment (compare $\mathrm{a}-\mathrm{f}$ and $\mathrm{a}^{\prime}-\mathrm{f}^{\prime}$ ).

\section{DISCUSSION}

Amyloid F, regardless of the precursor protein, display a common core structure that is characterized by the cross $\beta$ structure $(24,25)$. The structural properties, morphology, and kinetics of amyloid-fibril formation are strongly influenced by the amino acid sequence of the precursor protein as well as the changes in the solution conditions under which they were grown $(34,35)$. Studies from our laboratory and others have shown that the primary sequence of the constituent protein also plays an important role in modulating the protein-protein contacts within the fibril, thus influencing fibril stability $(23,36)$. For example, F composed of the wildtype $\alpha$-syn proved to be more stable to pressure denaturation than the F composed of the disease-linked variants (A53T and A30P). Also, the V30M variant of transthyretin (TTR) was incompletely dissociated by HHP, while the wild-type protein was completely dissociated in less than 5 min at 2500 bar (23).

In the case of $\beta 2 \mathrm{~m} \mathrm{~F}$, pressure treatment in the absence of any added denaturant induced their conversion into a species able to bind more Thio-T, suggesting that even the amyloid $\mathrm{F}$ can assume different conformation, and HHP is useful in revealing these new conformational states (37). Recently, Bosharova and collaborators were able to show that aggregates of the prion protein $(\mathrm{PrP})$, when subjected to heat treatment in the presence of Triton X-100, also undergo rearrangements within the amyloid core, resulting in the extension of the proteinase-K-resistant core. These data argue in favor of the existence of different fibrilar states, which might have important physiological implications in the ethiology of their respective diseases (38).

Recently, Dirix and co-workers also reported that early aggregates of a peptide from TTR were pressure-sensitive, while mature aggregates derived from the same peptide were pressure-resistant (36). These data are consistent with the results presented here, where we show that, in going from $\mathrm{PF}$ to $\mathrm{F}$, there is a gain in stability (mainly observed with wild type and A30P) (Table 1). Further, while all PF exhibited an identical susceptibility to HHP regardless of 
the primary sequence of the constituent protein, the F respond differently, with the $\mathrm{F}_{\mathrm{wt}}$ being the most stable among them. These results suggest that during fibrillogenesis several structural changes take place within the amyloid structure, as summarized below:

\begin{tabular}{|c|c|c|c|c|}
\hline monomer & $\rightarrow$ & $\mathrm{PF}$ & $\rightarrow$ & $\mathrm{F}$ \\
\hline $\begin{array}{c}\text { unpacked } \\
\text { no cavities } \\
\text { unstructured } \\
\text { highly hydrated }\end{array}$ & & $\begin{array}{c}\text { not well packed } \\
\text { cavities } \\
\text { main-chain contacts } \\
\text { less hydrated }\end{array}$ & & $\begin{array}{c}\text { well packed } \\
\text { fewer cavities } \\
\text { side-chain contacts } \\
\text { less hydrated }\end{array}$ \\
\hline
\end{tabular}

Differences in stability among all of these species are probably related to the presence of void volume and packing defects. In general, the species that are more susceptible to HHP are the ones with internal void volumes (water-excluded cavities), dry interfaces, and the presence of hydrophobic and electrostatic interactions (39-41).

Previous studies performed by Lansbury and others have shown that, with short incubation times, DA interacts with $\alpha$-syn and inhibits the conversion of PF into F (21). However, as shown here, upon longer incubations, mature amyloid $\mathrm{F}$ of $\alpha$-syn were observed to form in the presence of equimolar concentrations of DA, an observation that has not been reported before. It is possible that, with aging, a fraction of the $\alpha$-syn-bound DA molecules detach from the PF, allowing the latter to evolve into F. However, because the F grown in the absence and presence of DA responded differently to HHP treatment, we postulate that at least some DA molecules remain bound to the protein in the $\mathrm{F}$ and modulate their stability, possibly through modulating structural changes involved in protein-protein interactions within the $\mathrm{F}$.

The data presented here examine for the first time the idea that there is an effect of DA on the thermodynamic stability of the PF and $\mathrm{F}$ of $\alpha$-syn, with important correlations with PD etiology. Our data show clearly that DA exerts a considerable effect in modulating PF and F stability, and this modulation depends upon the protein that constitutes the aggregates (Figure 4). Variant PF, when grown in the presence of DA, exhibited a notable gain in stability (Figures 2 and 4), and this could be associated with their early onset in PD patients. Although other regions of the brain are also affected in patients bearing these mutations $(8)$, the dopaminergic region presents an increased susceptibility that has been attributed to the presence of the catecholamines. Thus, here, we propose an additional role of DA that is its differential modulation of the stability of the aggregate species of $\alpha$-syn. This stabilizing effect is not observed in the case of wild-type $\alpha$-syn, where $\mathrm{PF}_{\mathrm{wt}}$ and $\mathrm{DAPF}_{\mathrm{wt}}$ are equally stable under pressure (Figure 4). However, $\mathrm{DAF}_{\mathrm{wt}}$ is much more unstable than $F_{w t}$. It is tempting to suggest that, in the dopaminergic neurons, the presence of DA would render the $\mathrm{F}$ composed of wild-type $\alpha$-syn very labile, enhancing the possibility of their breaking into smaller, toxic species and causing damage specifically to this region of the brain. In nondopaminergic neurons, because of the absence of DA, $F_{w t}$ as a stable entity would remain as an inert material, sparing this region from damage. Considering that the vast majority of PD cases are sporadic and involve the wild-type protein, these observations have important physiological implications.
It is noteworthy that $\alpha$-syn aggregation and toxicity are also implicated in the pathogenesis of several neurodegenerative diseases, including Alzheimer's disease, multiplesystem atrophy, dementia with LB, Down syndrome, and neurodegeneration with brain iron accumulation, collectively referred to as synucleinopathies $(42,43)$. The presence of $\alpha$-syn aggregates within LB and Lewy neurites in brain regions other than the substantia nigra and within different population of neurons (dopaminergic and nondopaminergic) suggests that toxicity of the $\alpha$-syn aggregates does not depend exclusively upon the presence of DA. However, it is likely that the stability of $\alpha$-syn aggregates within these inclusions is also modulated by the interactions between $\alpha$-syn and other macromolecule, as well as by the post-translational modifications that take place with $\alpha$-syn.

To understand the role of DA in modulating the toxic properties of $\alpha$-syn aggregates, we evaluated the toxicity of $\mathrm{PF}_{\mathrm{A} 30 \mathrm{P}}$ and $\mathrm{DAPF}_{\mathrm{A} 30 \mathrm{P}}$ before and after HHP treatment using mesencephalic and cortical neurons in cultures (Figures 5 and 6). Our data show that the mesencephalic neurons seem to be more sensitive than cortical neurons to the presence of either aggregate, although the percentage of dopaminergic neurons in these cultures is in the range of $17-21 \%$ (44). Strikingly, when the neuronal cultures are incubated in the presence of samples treated under pressure at 2700 bar for $1 \mathrm{~h}$, these neurons present a healthy aspect, suggesting that the species rescued from high pressure loses its toxicity. AFM images (parts $\mathrm{C}-\mathrm{F}$ of Figure 1) revealed that, after pressure treatment, the average diameter of the spherical aggregates present before compression decreased significantly (Dunn's multiple comparison test, $p<0.01$ ), and this may explain the decrease in toxicity. Besides, nuclear fragmentation was observed in all cultures treated with $\mathrm{PF}_{\mathrm{A} 30 \mathrm{P}}$ and $\mathrm{DAPF}_{\mathrm{A} 30 \mathrm{P}}$ (Figure 5), and again, these effects are reversed by HHP treatment. It has been reported that the overexpression of human $\alpha$-syn in rat neuronal cells results in a significant reduction of neurite expansion (45). However, very few data in the literature describe the toxic effects of adding aggregates of $\alpha$-syn to neurons in culture as we show here. This approach has an important implication because the presence of $\alpha$-syn in plasma has recently been described (46). Besides, because the addition of aggregates is much easier than $\alpha$-syn transfection, it could be used as a first approach in drug screening.

The observation that the cytotoxicity of the $\mathrm{DAPF}_{\mathrm{A} 30 \mathrm{P}}$ is almost completely abolished after pressure treatment despite the fact that these PF are only partially dissociated by HHP (Figure 2 ) suggests that $\alpha$-syn toxicity is mediated by specific protofibrillar structures that are susceptible to pressure denaturation. Recently, in an elegant study, Silveira and coworkers (47) were able to isolate a subpopulation responsible for infectivity and by the converting activity of the $\operatorname{PrP}$ (res) in transmissible spongiform encephalopathy. This subpopulation contains aggregates of a size compatible with only 14-28 molecules of the PrP.

The mechanism by which these aggregates of $\alpha$-syn exert their toxic effects remains unclear now. An important question that arises from this observation is the precise site of action of these aggregates on the outside of the cells. Further studies are necessary to address this issue. 


\section{ACKNOWLEDGMENT}

The authors acknowledge Dr. Martha M. Sorenson for her kind reading of the manuscript. This work was supported in part by grants from the CNPq, CAPES, and FAPERJ to J.L.S. and D.F. and from a Grant from ICGEB to J.L.S. The authors acknowledge Emerson Gonçalves for technical support.

\section{REFERENCES}

1. Tanner, C. M. (1992) Occupational and environmental causes of parkinsonism, Occup. Med. 7, 503-513.

2. Spillantini, M. G., Schmidt, M. L., Lee, V. M., Trojanowsky, J. Q., Jakes, R., and Goldberg, M. (1997) $\alpha$-Synuclein in Lewy bodies, Nature 388, 839-840.

3. Forno, L. S. (1996) Neuropathology of Parkinson's disease, J. Neuropathol. Exp. Neurol. 55, 259-272.

4. Spillantini, M. G., Crowther, R. A., Jakes, R., Hasegawa, M., and Goedert, M. (1998) $\alpha$-Synuclein in filamentous inclusions of Lewy bodies from Parkinson's disease and dementia with Lewy bodies, Proc. Natl. Acad. Sci. U.S.A. 95, 6469-6473.

5. Baba, M., Nakajo, S., Tu, P. H., Tomita, T., Nakaya, K., Lee, V. M., Trojanowsky, J. Q., and Iwatsubo, T. (1998) Aggregation of $\alpha$-synuclein in Lewy bodies of sporadic Parkinson's disease and dementia with Lewy bodies, Am. J. Pathol. 152, 879-884.

6. Goedert, M., Spillantini, M. G., Serpell, L. C., Berriman, J., Smith, M. J., Jakes, R., and Crowther, R. A. (2001) From genetics to pathology: tau and $\alpha$-synuclein assemblies in neurodegenerative diseases, Philos. Trans. R. Soc. London, Ser. B 356, 213-227.

7. Cabin, D. E., Shimazu, K., Murphy, D., Cole, N. B., Gottschalk, W., McIlwain, K. L., Orrison, B., Chen, A., Ellis, C. E., Paylor, R., Lu, B., and Nussbaum, R. L. (2002) Synaptic vesicle depletion correlates with attenuated synaptic responses to prolonged repetitive stimulation in mice lacking $\alpha$-synuclein, J. Neurosci. 22, 8797-8807.

8. Cookson, M. R. (2005) The biochemistry of Parkinson's disease, Annu. Rev. Biochem. 74, 29-52.

9. . Polymeropoulos, M. H., Lavedan, C., Leroy, E., Ide, S. E., Dehejia, A., Dutra, A., Pike, B., Root, H., Rubenstein, J., Boyer, R., Stenroos, E. S., Chandrasekharappa, S., Athanassiadou, A., Papapetropoulos, T., Johnson, W. G., Lazzarini, A. M., Duvoisin, R. C., Di Iorio, G., Golbe, L. I., and Nussbaum, R. L. (1997) Mutation in the $\alpha$-synuclein gene identified in families with Parkinson's disease, Science 276, 2045-2047.

10. Kruger, R., Kuhn, W., Muller, T., Woitalla, D., Graeber, M., Kosel, S., Przuntek, H., Epplen, J. T., Schols, L., and Riess, O. (1998) Ala30Pro mutation in the gene encoding $\alpha$-synuclein in Parkinson's disease, Nat. Genet. 18, 106-108.

11. Conway, K. A., Lee, S. J., Rochet, J. C., Ding, T. T., Williamson, R. E., and Lansbury, P. T. (2000) Acceleration of oligomerization, not fibrillization, is a shared property of both $\alpha$-synuclein mutations linked to early-onset Parkinson's disease: Implications for pathogenesis and therapy, Proc. Nat. Acad. Sci. U.S.A. 97, 571-576.

12. Singleton, A. B., Farrer, M., Johnson, J., Singleton, A., Hague, S., Kachergus, J., Hulihan, M., Peuralinna, T., Dutra, A., Nussbaum, R., Lincoln, S., Crawley, A., Hanson, M., Maraganore, D., Adler, C., Cookson, M. R., Muenter, M., Baptista, M., Miller, D., Blancato, J., Hardy, J., and Gwinn-Hardy, K. (2003) $\alpha$-Synuclein locus triplication causes Parkinson's disease, Science 302 , $841-843$.

13. Recchia, A., Debetto, P., Negro, A., Guidolin, D., Skaper, S., and Giusti, P. (2004) $\alpha$-Synuclein and Parkinson's disease, FASEB J. $18,617-626$.

14. Goldberg, M. S., and Lansbury, P. T. (2000) Is there a causeand-effect relationship between $\alpha$-synuclein fibrillation and Parkinson's disease? Nat. Cell Biol. 2, 115-119.

15. Rochet, J. C., Outeiro, T. F., Conway, K. A., Ding, T. T., Volles, M. J., Lashuel, H. A., Bieganski, R. M., Lindquist, S. L., and Lansbury, P. T. (2004) Interactions among $\alpha$-synuclein, dopamine, and biomembranes: Some clues for understanding neurodegeneration in Parkinson's disease, J. Mol. Neurosci. 23, 23-34.

16. Masliah, E., Rockenstein, E., Veinbergs, I., Mallory, M., Hashimoto, M., Takeda, A., Sagara, Y., Sisk, A., and Mucke, L. (2000) Dopaminergic loss and inclusion body formation in $\alpha$-synuclein mice: Implications for neurodegenerative disorders, Science 87, $1265-1269$.
17. Li, J., Uversky, V. N., and Fink, A. L. (2001) Effect of familial Parkinson's disease point mutations A30P and A53T on the structural properties, aggregation, and fibrillation of human $\alpha$-synuclein, Biochemistry 40, 11604-11613.

18. Li, J., Uversky, V. N., and Fink, A. L. (2002) Conformational behavior of human $\alpha$-synuclein is modulated by familial Parkinson's disease point mutations A30P and A53T, Neurotoxicology $23,553-567$.

19. Greenbaum, E. A., Graves, C. L., Mishizen-Eberz, A. J., Lupoli, M. A., Lynch, D. R., Englander, S. W., Axelsen, P. H., and Giasson, B. I. (2005) The E46K mutation in $\alpha$-synuclein increases amyloid fibril formation, J. Biol. Chem. 280, 7800-7807.

20. Volles, M. J., and Lansbury, P. T. (2002) Vesicle permeabilization by protofibrillar $\alpha$-synuclein is sensitive to Parkinson's diseaselinked mutations and occurs by a pore-like mechanism, Biochemistry 41, 4595-4602.

21. Conway, K. A., Rochet, J. C., Bieganski, R. M., and Lansbury, P. T. (2001) Kinetic stabilization of the $\alpha$-synuclein protofibril by a dopamine- $\alpha$-synuclein adduct, Science 294, 1346-1349.

22. Li, J., Zhu, M., Manning-Bog, A. B., Di Monte, D. A., and Fink, A. L. (2004) Dopamine and L-dopa disaggregate amyloid fibrils: Implications for Parkinson's and Alzheimer's disease, FASEB J. $18,962-964$

23. Foguel, D., Suarez, M. C., Ferrão-Gonzales, A. D., Porto, T. C. R., Palmieri, L., Einsiedler, C. M., Andrade, L. R., Lashuel, H. A., Lansbury, P. T., Kelly, J. W., and Silva, J. L. (2003) Dissociation of amyloid fibrils of $\alpha$-synuclein and transthyretin by pressure reveals their reversible nature and the formation of water-excluded cavities, Proc. Natl. Acad. Sci. U.S.A. 100, 98319836.

24. Nelson, R., Sawaya, M. R., Balbirnie, M., Madsen, A. O., Riekel, C., Grothe, R., and Eisenberg, D. (2005) Structure of the cross- $\beta$ spine of amyloid-like fibrils, Nature 435, 747-749.

25. Tycko, R. (2006) Molecular structure of amyloid fibrils: Insights from solid-state NMR, Q. Rev. Biophys. 1-55.

26. Cappai, R., Leck, S. L., Tew, D. J., Williamson, N. A., Smith, D. P., Galatis, D., Sharples, R. A., Curtain, C. C., Ali, F. E., Cherny, R. A., Culvenor, J. G., Bottomley, S. P., Masters, C. L., Barnham, J. K., and Hill, A. F. (2005) Dopamine promotes $\alpha$-synuclein aggregation into SDS-resistant soluble oligomers via a distinct folding pathway, FASEB J. 19, 1377-1379.

27. Conway, K. A., Harper, J. D., and Lansbury, P. T. (1998) Accelerated in vitro fibril formation by a mutant $\alpha$-synuclein linked to early-onset Parkinson disease, Nat. Med. 4, 1318-1320.

28. Silva, J. L., Silveira, C. F., Correa, A., and Pontes, L. (1992) Dissociation of a native dimer to a molten globule monomer. Effects of pressure and dilution on the association equilibrium of arc repressor, J. Mol. Biol. 223, 545-555.

29. Prochiantz, A., Daguet, M. C., Herbet, A., and Glowinski, J. (1981) Specific stimulation of in vitro maturation of mesencephalic dopaminergic neurons by striatal membranes, Nature 293, 570572 .

30. Garcia-Abreu, J., Neto, V. M., Carvalho, S. L., and Cavalcante, L. A. (1995) Regionally specific properties of midbrain glia: I. Interactions with midbrain neurons, J. Neurosci. Res. 40, 471477.

31. Sousa, V. de O., Romao, L., Neto, V. M., and Gomes, F. C. (2004) Glial fibrillary acidic protein gene promoter is differently modulated by transforming growth factor- $\beta 1$ in astrocytes from distinct brain regions, Eur. J. Neurosci. 19, 1721-1730.

32. Volles, M. J., and Lansbury, P. T. (2003) Zeroing in on the pathogenic form of $\alpha$-synuclein and its mechanism of neurotoxicity in Parkinson's disease, Biochemistry 42, 7871-7878.

33. Norris, E. H., Giasson, B. I., Hodara, R., Xu, S., Trojanowski, J. Q., Ischiropoulos, H., and Lee, V. M. (2005) Reversible inhibition of $\alpha$-synuclein fibrillization by dopaminochrome-mediated conformational alterations, J. Biol. Chem. 280, 21212-21219.

34. Jimenez, J. L., Tennent, G., Pepys, M., and Saibil, H. R. (2001) Structural diversity of ex vivo amyloid fibrils studied by cryoelectron microscopy, J. Mol. Biol. 311, 241-247.

35. Petkova, A. T., Leapman, R. D., Guo, Z., Yau, W. M., Mattson, M. P., and Tycko, R. (2005) Self-propagating, molecular-level polymorphism in Alzheimer's $\beta$-amyloid fibrils, Science 307 , $262-265$

36. Dirix, C., Meersman, F., MacPhee, C. E., Dobson, C. M., and Heremans, K. (2005) High hydrostatic pressure dissociates early aggregates of TTR105-115, but not the mature amyloid fibrils, $J$. Mol. Biol. 347, 903-909. 
37. Chatani, E., Naiki, H., and Goto, Y. (2006) Seeding-dependent propagation and maturation of $\beta 2$-microglobulin amyloid fibrils under high pressure, J. Mol. Biol. 359, 1086-1096.

38. Bosharova, O. V., Makarava, N., Breydo, L., Anderson, M. Salnikov, V. V., and Baskakov, I. V. (2006) Annealing prion amyloid fibrils at high temperature results in extension of a proteinase-K resistant core, J. Biol. Chem. 281, 2371-2379.

39. Foguel, D., and Silva, J. L. (2004) New insights into the mechanisms of protein misfolding and aggregation in amyloidogenic diseases derived from pressure studies, Biochemistry $43,11361-11370$.

40. Grudzielanek, S., Smirnovas, V., and Winter, R. (2006) Solvationassisted pressure tuning of insulin fibrillation: From novel aggregation pathways to biotechnological applications, J. Mol. Biol. 356, 497-509.

41. Cordeiro, Y., Kraineva, J., Ravindra, R., Lima, L. M., Gomes, M. P., Foguel, D., Winter, R., and Silva, J. L. (2004) Hydration and packing effects on prion folding and $\beta$-sheet conversion. High pressure spectroscopy and pressure perturbation calorimetry studies, J. Biol. Chem. 279, 32354-32359.

42. Lansbury, P. T., and Lashuel, H. A. (2006) A century-old debate on protein aggregation and neurodegeneration enters the clinic, Nature 443, 774-779.
43. Dev, K. K., Hofele, K., Barbieri, S., Buchman, V. L., and van der Putten, H. (2003) Part II: $\alpha$-Synuclein and its molecular pathophysiological role in neurodegenerative disease, Neuropharmacology 45, 14-44.

44. Shimoda, K., Sauve, Y., Marini, A., Schwartz, J. P., and Commissiong, J. W. (1992) A high percentage yield of tyrosine hydroxylase-positive cells from rat E14 mesencephalic cell culture, Brain Res. 586, 319-331.

45. Takenouchi, T., Hashimoto, M., Hsu, L. J., Mackowski, B., Rockenstein, E., Mallory, M., and Masliah, E. (2001) Reduced neuritic outgrowth and cell adhesion in neuronal cells transfected with human $\alpha$-synuclein, Mol. Cell. Neurosci. 17, 141-150.

46. Lee, H. J., Patel, S., and Lee, S. J. (2005) Intravesicular localization and exocytosis of $\alpha$-synuclein and its aggregates, J. Neurosci. 25, 6016-6024.

47. Silveira, J. R., Raymond, G. J., Hughson, A. G., Race, R. E., Sim, V. L., Hayes, S. F., and Caughey, B. (2005) The most infectious prion protein particles, Nature 437, 257-261.

$\mathrm{BI} 061871+$ 